\title{
Núcleos de terras degradadas do campo calcário Aroeiras e adjacências, Municípios de Coreaú e Sobral (Ceará)
}

\section{Land degradation cores in the Aroeiras limestone field and surroundings, municipalities of Coreaú and Sobral (Ceará)}

\section{Núcleos de tierras degradadas en el campo de roca caliza de Aroeiras y sus alrededores, municipios de Coreaú y Sobral (Ceará)}

Francisco Nataniel Batista de Albuquerque ${ }^{1}$ https://orcid.org/0000-0001-8588-2740

\footnotetext{
1 Dr. Em Geografia, Professor do Curso de Licenciatura em Geografia do Instituto Federal do Ceará (IFCE), Campus Iguatu e do Mestrado em Geografia da Universidade Estadual Vale do Acaraú (UVA), Sobral-Ceará-Brasil, natangeo@ hotmail.com
}

Recebido em: 23/05/2020

Aceito para publicação em: 30/09/2020

\section{Resumo}

A pesquisa analisa a degradação das terras no campo calcário Aroeiras e adjacências, geossistema apropriado como território da produção de cal e cimento nos municípios de Coreaú e Sobral na região noroeste do Estado do Ceará. Do ponto de vista metodológico, o mapa de uso e cobertura das terras permitiu detectar que os três núcleos de terras degradados identificados estão quase que, exclusivamente, fora do campo Aroeiras, evidenciando uma baixa correlação com a litologia carbonática da formação Frecheirinha e elevada com as formações Coreaú e Trapiá. A degradação nos núcleos está associada ao desmatamento da Caatinga sem controle, enquanto os núcleos conservados correspondem a grandes áreas de plano de manejo florestal e amortecimento aos impactos da mineração de grande porte.

Palavras-chave: Degradação de Terras. Litologia. Extrativismo Vegetal.

\begin{abstract}
The research analyzes the land degradation in the Aroeiras limestone field and surroundings, an appropriate geosystem as a territory for the production of quicklime and cement in the municipalities of Coreaú and Sobral in the northwest region of the State of Ceará. From the methodological point of view, the map of land use and coverage allowed to detect that the three land degradation cores identified are almost exclusively outside the Aroeiras field, showing a low correlation with the carbonate lithology of the Frecheirinha formation and high with the Coreaú and Trapiá formations.Degradation in the core is associated with
\end{abstract}


deforestation in the Caatinga without control, while the conserved cores correspond to large areas of forest management plan and dampening the impacts of large mining.

Keywords: Land degradation. Lithology. Plant extractivism.

\section{Resumen}

La investigación analiza la degradación de las tierras en el campo de roca caliza de Aroeiras y sus alrededores, un geosistema apropiado como territorio para la producción de cal y cemento en los municipios de Coreaú y Sobral en la región noroeste del estado de Ceará. Desde el punto de vista metodológico, el mapa de uso y cobertura de la tierra nos permitió detectar que los tres núcleos de tierra degradada identificados están casi exclusivamente fuera del campo de Aroeiras, mostrando una baja correlación con la litología de carbonatos de la formación Frecheirinha y alta con las formaciones Coreaú y Trapiá. La degradación en los núcleos se asocia con la deforestación de la Caatinga sin control, mientras que los núcleos conservados corresponden a grandes áreas de plan de manejo forestal y amortiguamiento de los impactos de la gran minería.

Palabras clave: Degradación de la tierra. Litología. Extracción de plantas.

\section{Introdução}

A degradação das terras é um problema global, porém, nas regiões secas esse quadro assume algumas especificidades em função da suscetibilidade natural ao fenômeno climático das secas, aliado a atividades humanas com grande pressão sobre os recursos naturais resultando em, situações extremas, no processo de desertificação (WESTING, 1994; MATALLO JÚNIOR, 2001; CHERLET, et al., 2018), fenômeno que exige por parte do poder público e da sociedade civil medidas de prevenção e combate nas esferas política, econômica, ambiental e educacional.

Conceitualmente, entende-se por terra o "sistema bio-produtivo terrestre que compreende solo, vegetação, biota e os processos ecológicos e hidrológicos que operam dentro do sistema" (MATALLO JÚNIOR, 2009, p. 74) e, degradação de terras, a deterioração ou perda total da capacidade dos solos para uso presente e futuro (FAO, 1980).

Quando o quadro de degradação de terras apresenta-se em estágio muito avançado e localizado em regiões secas do globo, têm-se a desertificação, produto de uma interação entre sistemas sociais vulneráveis e modelos produtivos superexploratórios dos sistemas naturais, aliado a suscetibilidade significativa de seus elementos. A desertificação é definida pela United Nations Convention to Combat Desertification (UNCCD, 1995, p. 04) como "a 
degradação da terra nas zonas áridas, semiáridas e subúmidas secas, resultante de vários fatores, incluindo as variações climáticas e as atividades humanas".

No Semiárido Brasileiro, a desertificação atinge áreas em função das características climáticas marcadas pela semiaridez, configurando-se, do ponto de vista natural, como áreas suscetíveis à desertificação (ASD) compreendendo $1.340 .863 \mathrm{~km}^{2}$, envolvendo 1.488 municípios de 11 Estados. Nesse contexto regional, o Ministério do Meio Ambiente identifica 04 núcleos de desertificação: Cabrobó (Pernambuco), Irauçuba (Ceará), Seridó (Rio Grande do Norte e Paraíba) e Gilbués (Piauí) (PEREZ-MARIN et al., 2012).

Vale ressaltar que alguns pesquisadores (SALES, 1997; SILVA, 2014), não classificam Gilbués como núcleo de desertificação, por apresentar índice de aridez superir a 0,65 resultado de características litológicas (arenitos), vegetacionais (Cerrado) e climáticas (médias pluviométricas em torno de acima de $1100 \mathrm{~mm} /$ anuais e curto período seco) muito diferentes do quadro de semiaridez. Silva (2014) utiliza o conceito de arenização e não desertificação para referir-se a degradação das terras no "núcleo" do Piauí.

No Estado do Ceará, onde 92\% do território encontra-se sob condições de semiaridez, a Fundação Cearense de Meteorologia e Recursos Hídricos (Funceme) (1992) aponta áreas suscetíveis à desertificação definindo dois eixos latitudinais, o eixo leste, que estende-se pelo vale do Médio Jaguaribe e, o eixo oeste, que estende-se desde os Inhamuns até o Vale do Acaraú, com um prolongamento a noroeste.

Outro estudo importante foi realizado pelo Centro de Gestão e Estudos Estratégicos (CGEE) (2016) em parceria com a Funceme indicando a ocorrência de três áreas que totalizam 17 mil $\mathrm{km}^{2}$ de áreas degradadas $(11,45 \%$ do Estado do Ceará) com destaque para o município de Irauçuba, um dos núcleos de desertificação apontados pelo PAN-Brasil. As três áreas são: a região dos Inhamuns/Sertões de Crateús; o município de Irauçuba e regiões circunvizinhas e; o Médio Jaguaribe. Vale ressaltar que nos dois estudos, o Alto Coreaú e outras áreas da bacia hidrográfica homônima estão identificadas como fortemente degradadas, incluindo a área de estudo da referida pesquisa, o campo calcário Aroeiras.

Em estudo realizado por Albuquerque (2015) no geossistema da Depressão Interplanáltica Semiárida do Alto Coreaú (DISAC), região noroeste do Estado do Ceará entre o maciço residual da Meruoca e o planalto da Ibiapaba, constatou-se que os maiores índices de degradação ambiental estão na porção leste, área mais seca e de abrangência do campo calcário Aroeiras guardando grande relação com a área identificada por Funceme (1992) e CGEE (2016). 
Na comparação entre os campos calcários do geossistem, a área ocupada pelo campo Aroeiras e suas adjacências na porção leste do geossistema é a que possui os maiores níveis de degradação ambiental (ALBUQUERQUE, 2015) e o maior número de unidades produtivas de cal da região em comparação com a porção oeste mais úmida, área de predominância do campo Frecheirinha (ALBUQUERQUE, 2019).

Inúmeros são os fatores responsáveis pela degradação das terras. Sá et al. (1994) e Matallo Júnior (2001) apontam dentre outros fatores, a pecuária e a agricultura, como as principais responsáveis pela degradação das terras no Brasil. No Semiárido Brasileiro, a matriz energética ainda muito dependente do uso indiscriminado de plantas da Caatinga acarreta na degradação da cobertura vegetal principalmente pela agropecuária e extrativismo (CGEE, 2016).

Muito embora a mineração seja apontada como uma das principais atividades responsáveis pela degradação de terras (KOPEZINSKI, 2000), outros estudos apontam a mineração como alternativa ao combate à desertificação no Semiárido Brasileiro (DNPM, 2009) revelando as várias facetas da relação degradação x conservação dos recursos naturais, porém, ratificando a mineração como geradora de grandes inputs no manejo dos recursos naturais.

Cordani e Taioli (2009) apontam, por exemplo, que na serra de Carajás na Amazônia, entre os anos de 1975 e 1999 registrou-se um intenso desmatamento para a implantação de atividades agropecuárias, enquanto que a área sob a responsabilidade da mineração manteve a floresta preservada. É preciso relativizar a informação, principalmente no que concernem as escalas espaciais de cada atividade (agropecuária e mineração) e a escala de análise adotada nas pesquisas, por exemplo.

Essa prática predatória tem levado ao aparecimento no Semiárido Brasileiro de muitas áreas com sérios problemas de conservação dos recursos naturais, algumas delas irreversíveis a curto e médio prazo, sendo caracterizados como áreas ou núcleos de desertificação. Essas áreas são, ao mesmo tempo, reflexo e condicionante do processo de degradação humana dos sertanejos, pela falta de uma política eficiente para enfrentamento dos problemas regionais que são além de naturais, sócio-políticos e econômicos (DANTAS et al., 2006).

Diante desse contexto temático e regional, o objetivo da pesquisa é identificar os núcleos de terras degradadas do campo Aroeiras, área de ocorrência geológica de calcário e território de produção artesanal da cal e industrial de cimento, a partir da suscetibilidade da 
litologia e da vulnerabilidade e pressão das atividades antropogênicas situadas na região noroeste do Ceará, mais exatamente no limite entre os municípios de Coreaú e Sobral

\section{Área de estudo e metodologia}

A área de estudo, o campo calcário Aroeiras consiste numa poligonal de aproximadamente $79 \mathrm{~km}^{2}$ de ocorrência geológica da rocha calcária localizado no limite entre os municípios de Coreaú e Sobral tendo como principais pontos de referência espacial os distritos de Aroeiras (0338’34” S; 40³7’21” W), Ubaúna (0344’26” S; 4041’26” W) e Aprazível (0345’11” S; 40³3’30” W) (Carta Imagem 1).

Carta Imagem 1- Localização da área de estudo no geossistema da Depressão Interplanáltica Semiárida do Alto Coreaú (DISAC).

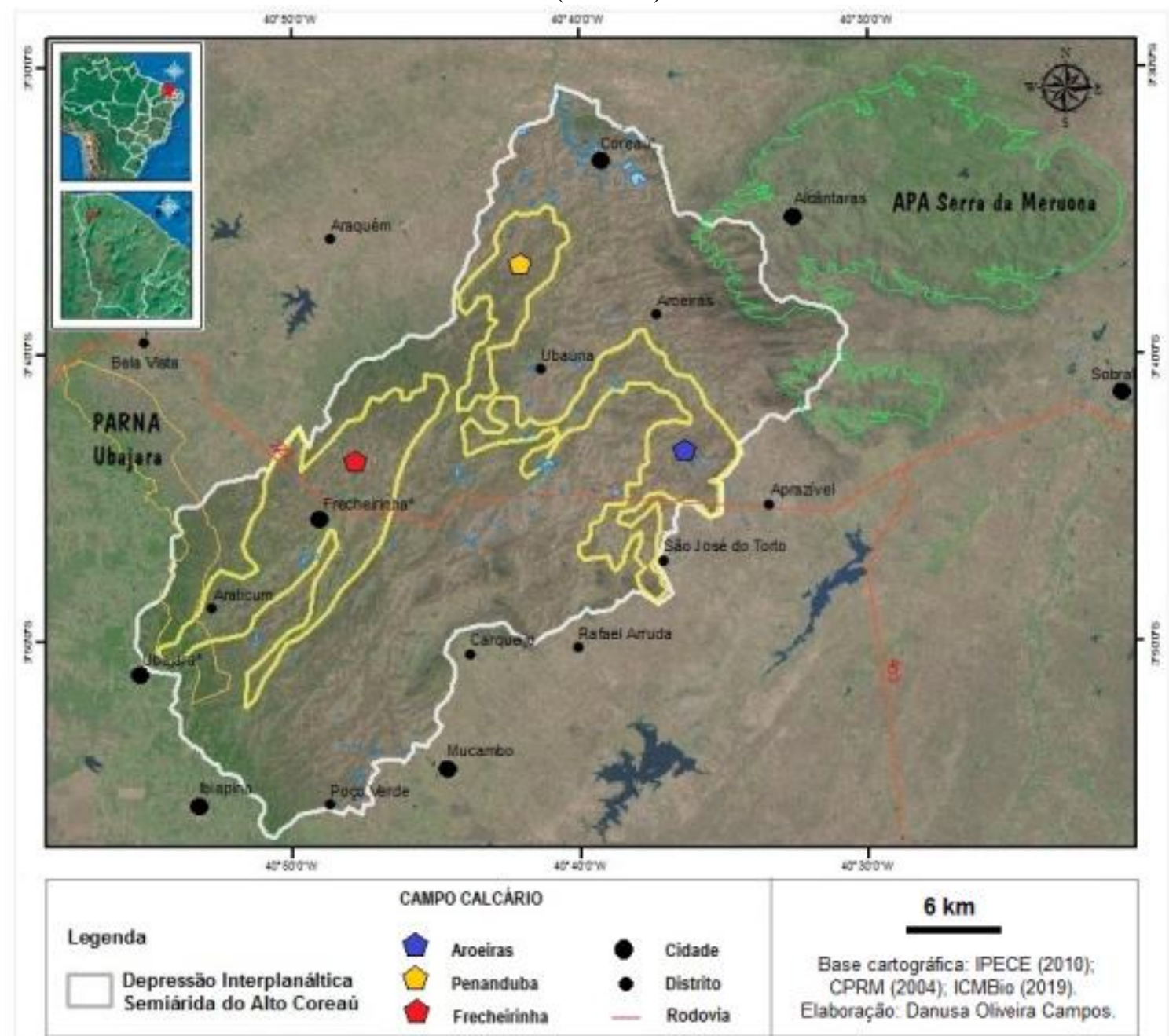

Fonte: Imagem Landsat Inpe(2011), Elaboração cartográfica Danusa Oliveira Campos (2019)

O campo Aroeiras configura-se como um importante e histórico território de produção da cal e do cimento no contexto regional e estadual com a presença da unidade fabril de

Geopauta, Vitória da Conquista, ISSN: 2594-5033, V. 4, n.3, 2020, p.(180-194) http://periodicos2.uesb.br/index.php/geo, 
cimento do grupo Votorantim e de dezenas de tradicionais caieiras, fornos rudimentares de produção da cal (BNB, 1987; ALBUQUERQUE, 2019) situado na região do Alto Coreaú (CE), entre as encostas secas do maciço residual da Meruoca, a leste e, e as escarpas úmidas do planalto da Ibiapaba, a oeste apresentando desníveis altimétricos que chegam a 700 metros entre a depressão Sertaneja e os topos das principais feições geomorfológicas adjacentes citadas onde encontram-se duas unidades de conservação federal de grande importância, a área de proteção ambiental da Serra da Meruoca e o parque nacional de Ubajara.

Do ponto de vista metodológico, a pesquisa articula pesquisa bibliográfica, interpretação de produtos de sensoriamento remoto e trabalhos de campo para validação da análise em gabinete.

O campo calcário Aroeiras foi delimitado a partir dos dados da Companhia de Pesquisas de Recursos Minerais (CPRM), enquanto para a confecção do mapa de uso e cobertura da terra utilizou-se imagem do satélite Landsat 7 do ano de 2011, devido a intensa cobertura de nuvens o que dificulta a escolha da mesma. A checagem em campo foi realizada em 2015 com auxílio de um receptor de Global Positioning System (GPS).

Para a identificação dos elementos texturais para o reconhecimento das formas de uso da terra foi utilizado o programa ArcGis 9.2 e seus módulos (Analysis Tools, Spatial Analyst Tools, Spatial Statistics Tools).

As áreas adjacentes ao campo Aroeiras foram incluídas na análise espacial para permitir a comparação da degradação das terras na área interna e externa a poligonal do campo geológico permitindo a identificação das áreas degradadas, as quais denominamos de núcleo de terras degradadas (NTD), bem como a análise da correlação espacial formação geológica - terras degradadas.

\section{Núcleos de terras degradadas: suscetibilidade do sistema natural}

No contexto regional do geossistema da Depressão Interplanáltica Semiárida do Alto Coreaú (DISAC) registra-se a ocorrência de três campos calcários perfazendo uma área total de $231 \mathrm{~km}^{2}$ (quadro 1) historicamente explorados e beneficiados para a produção artesanal da cal e industrial do cimento abrangendo áreas dos municípios de Coreaú, Frecheirinha, Sobral, Ubajara e Ibiapina, por ordem de extensão. 
$\mathrm{Na}$ escala do geossistema, a porção leste da área corresponde ao setor mais seco da unidade territorial siatuada a sotavento da encosta ocidental do maciço da Meruoca (ALBUQUERQUE, 2015), justamente, em linhas gerais, na área de ocorrência do campo Aroeiras e das dezenas de unidades produtivas de cal que demandam elevadas quantidades de lenha para a combustão dos fornos, conhecidos como caieiras (ALBUQUERQUE, 2019).

Quadro 1- Extensão dos campos calcários e os respectivos municípios de abrangência.

\begin{tabular}{|c|c|c|}
\hline Campo calcário & Dimensão $\left(\mathbf{k m}^{\mathbf{2}}\right)$ & Municípios* \\
\hline Frecheirinha & 115 & Frecheirinha, Ubajara, Coreaú e Ibiapina \\
\hline Aroeiras & 79 & Coreaú e Sobral \\
\hline Penanduba & 37 & Coreaú \\
\hline Total & $\mathbf{2 3 1}$ & --- \\
\hline
\end{tabular}

*Os municípios estão em ordem por área de abrangência do campo calcário.

Fonte: elaborado pelo autor com base no mapeamento da área de estudo (2020).

$\mathrm{Na}$ escala do campo Aroeiras e entorno, uma das fáceis do geossistema foram identificados três núcleos de terras degradadas (NTD), áreas com elevado grau de degradação e significativa representação espacial, as quais foram denominadas de NTD Norte, Sul e Leste (Qudro 2).

Quadro 2 - Principais aglomerados populacionais dos NTD's.

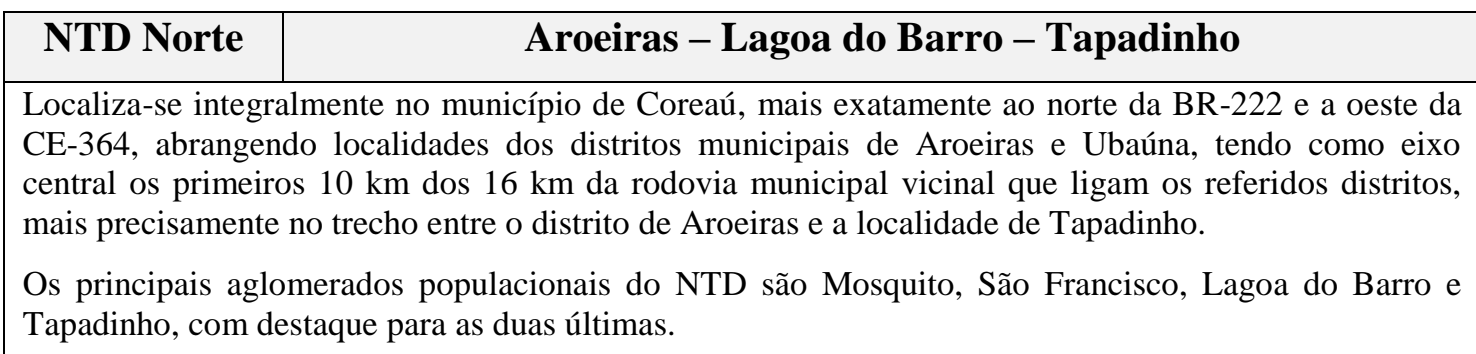

\section{NTD Sul}

Cajazeira - Ubaúna - Ipu dos Lopes

Localiza-se quase que exclusivamente no município de Coreaú, além de uma pequena parte do município de Sobral, na porção leste do núcleo abrangendo localidades dos distritos municipais de Ubaúna (Coreaú) e Aprazível (Sobral), cortando a rodovia federal BR-222 entre os km 263 e 271.

O distrito de Ubaúna e as localidades de Cajazeira, Conceição, Caia e Ipu dos Lopes são os principais aglomerados populacionais do NTD, além da presença de extensos "vazios demográficos".

Abrange áreas de contribuição do rio Caia e seus afluentes na porção leste e, na porção oeste, na bacia de contribuição direta do açude Trapiá III comprometendo o aporte de água do reservatório, o maior da área estudada com $5,5 \mathrm{mi} \mathrm{m}^{3}$.

\section{NTD Leste $\quad$ Pau D'Arco - Pedra de Fogo - Ponta da Serra}

Localiza-se no município de Sobral, entre entre as localidades de Pau D'Arco, Pedra de Fogo e Ponta da Serra, pertencentes ao distrito de Aprazível, as quais acompanham o eixo da rodovia estadual CE364 por $10 \mathrm{~km}$, dos quais $1,5 \mathrm{~km}$ estão fora da área de estudo nas imediações da localidade de Pau D’Arco, divisa entre as bacias do Coreaú e Acaraú.

Os principais aglomerados populacionais do NTD são respectivamente, Pedra de Fogo e Ponta da

Geopauta, Vitória da Conquista, ISSN: 2594-5033, V. 4, n.3, 2020, p.(180-194) http://periodicos2.uesb.br/index.php/geo, 
Serra.

Fonte: Elaborado pelo autor com base nos trabalhos de campo (2020).

A correlação espacial entre os dados de cobertura vegetal regional e a poligonal do campo geológico permite-nos perceber a baixa relação entre a fácie carbonática e os níveis de degradação das terras perfazendo um total de apenas $4,5 \%$ de sobreposição, pelo menos nessa escala de análise geográfica e cartográfica (quadro 3)

Quadro 3- Área dos núcleos de terras degradadas internas ao campo Aroeiras.

\begin{tabular}{|c|c|c|c|c|}
\hline \multirow[t]{3}{*}{ Núcleo } & \multicolumn{2}{|c|}{ Área Total Degradada } & \multirow{2}{*}{\multicolumn{2}{|c|}{$\begin{array}{c}\text { Área Degradada no } \\
\text { Campo Aroeiras }\end{array}$}} \\
\hline & \multirow[t]{2}{*}{$\mathbf{k m}^{2}$} & \multirow[t]{2}{*}{ ha } & & \\
\hline & & & $(\%)$ & Hectare \\
\hline Norte & 21 & 2.123 & 0,8 & 17,0 \\
\hline Sul & 44 & 4.401 & 0,9 & 36,6 \\
\hline Leste & 16 & 1.593 & 19,4 & 309,0 \\
\hline Total & 81 & 8.097 & 4,5 & 362,6 \\
\hline
\end{tabular}

Fonte: Albuquerque (2020).

Dentre os núcleos de terras degradadas, o NTD Leste destaca-se por possuir um percentual significativo de quase $1 / 5$ de sua área dentro do campo Aroeiras, enquanto, os NTD Norte e Sul possuem percentuais ínfimos que não atingem 1\% (Carta imagem 2).

As áreas degradadas acompanham, em linhas gerais, os eixos das principais rodovias que cortam o campo calcário, seja, a federal (NTD Sul), a estadual (NTD Leste) e a municipal vicinal (NTD Norte) colocando as rodovias como os principais vetores espaciais que colaboram diretamente para o acesso ao uso e ocupação mais intenso das áreas.

Um dos fatores que contribuem para o quadro de degradação do NTD Leste é a elevada densidade populacional com significativo número de residências e propriedades rurais nas margens da CE-364, o principal vetor de atração econômica do núcleo. Albuquerque (2019) ressalta que, mesmo com a decadência da atividade da produção da cal na região, essa área concentra o maior número de caieiras em atividade no ano de 2015 em todo o geossitema. 
Carta Imagem 2 - Núcleos de terras degradadas do campo Aroeiras e adjacências.

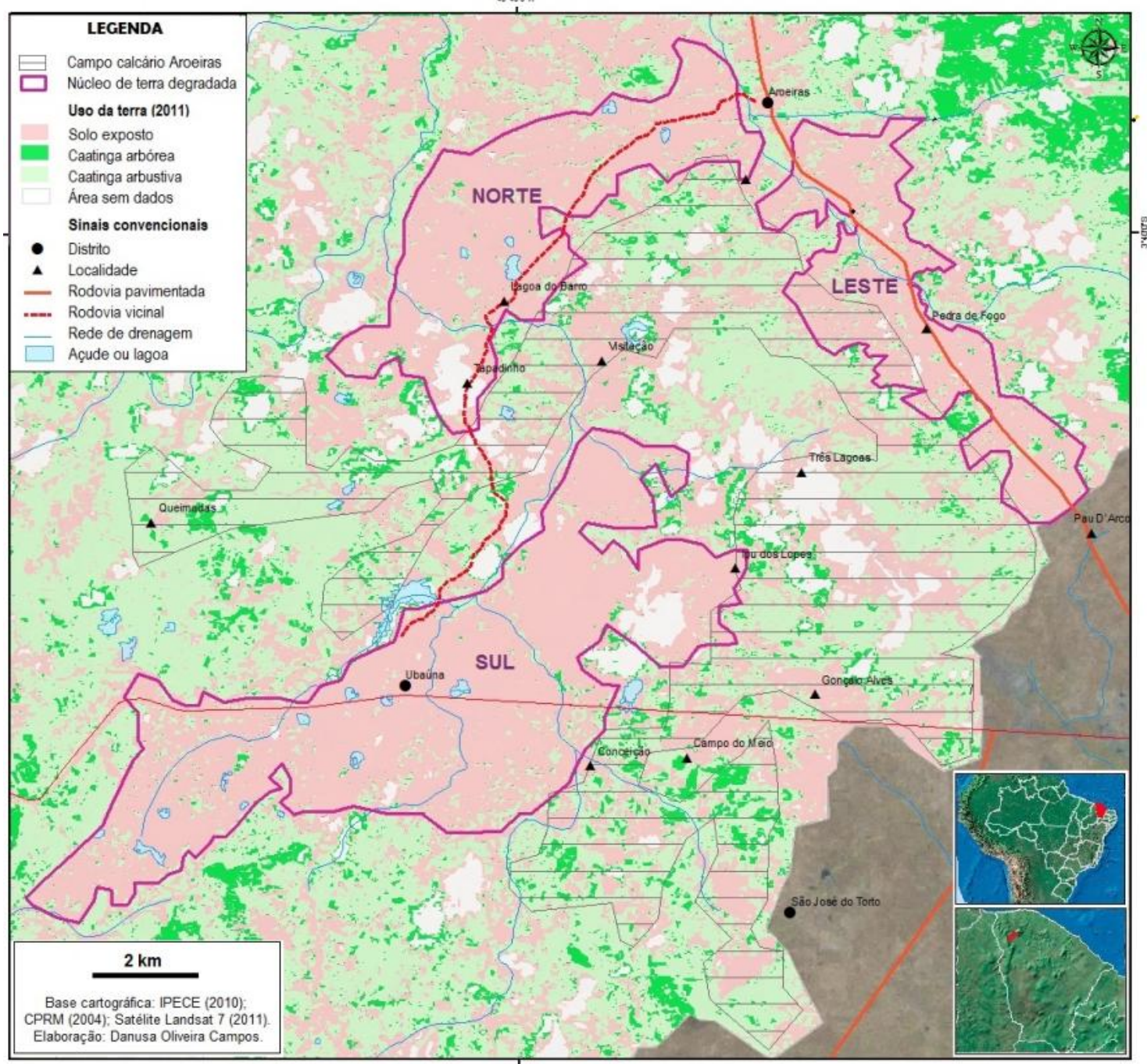

Fonte: Imagem Landsat Inpe(2011), Elaboração cartográfica Danusa Oliveira Campos (2015)

Em função da pequena área degradada na parte interna ao campo Aroeiras (formação Frecheirinha), partimos para a correlação espacial das áreas degradadas com as demais formações geológicas do grupo Ubajara, onde foi possível constatar que as terras degradadas estão principalmente nas formações Coreaú e Trapiá, respectivamente e, em menor grau, nas Formações: Caiçara e Frecheirinha, esta última de ocorrência dos calcários (Quadro 4).

Quadro 4 - Relação entre os núcleos de terras degradadas e a litologia regional.

\begin{tabular}{|c|c|c|c|c|c|}
\hline Grupo & $\begin{array}{c}\text { Formação geológica } \\
\text { sistema deposicional }\end{array}$ & Litologia & \multicolumn{2}{|c|}{ NTD (\%) } \\
\cline { 3 - 6 } & $\begin{array}{c}\text { Coreaú } \\
\text { (fluvial) }\end{array}$ & $\begin{array}{c}\text { Arenito arcoseano, grauvaca e } \\
\text { conglomerado }\end{array}$ & 99 & - & 81 \\
& Frecheirinha & $\begin{array}{c}\text { Calcário e marga com intercalações } \\
\text { de siltito e quartzito }\end{array}$ & 01 & 01 & 19 \\
\cline { 2 - 6 } & Ubajara & Ardósia, arenito e siltito & - & 04 & - \\
\cline { 2 - 6 } & Caiçara & Sul & & \\
\hline
\end{tabular}

Geopauta, Vitória da Conquista, ISSN: 2594-5033, V. 4, n.3, 2020, p.(180-194) http://periodicos2.uesb.br/index.php/geo, 


\begin{tabular}{|c|c|c|c|c|}
\hline (marinho raso) & anquimetamórficos & & & \\
\hline $\begin{array}{c}\text { Trapiá } \\
\text { (flúvio-marinho) }\end{array}$ & $\begin{array}{l}\text { Arenito grosso a conglomerático } \\
\text { anquimetamórficos }\end{array}$ & - & 95 & - \\
\hline \multicolumn{2}{|c|}{ Total } & 100 & 100 & 100 \\
\hline
\end{tabular}

Fonte: Albuquerque (2020).

É comum nas paisagens das formações Trapiá e Coreaú a presença de pequenas colinas que destacam-se na pediplano com pavimentos detríticos que denunciam o grau de denudação e degradação destas áreas, sendo muito comum os afloramentos rochosos e altos pelados conforme referencia Ab'Saber (1977) como sendo um dos geótopos secos. A formação Caiçara, por sua vez, apresenta um modelado acidentado onde se destacam cristas alinhadas de quartzitos (GEOPLAN, 1989) constituindo-se em pequenos inselbergs secos, onde a declividade dificulta o processo de ocupação direta e a baixa taxa de vulnerabiliade dos quartzitos à denudação segundo Crepani et al. (2001), coloca essas feições em posição de destaque na paisagem.

Já o calcário da formação Frecheirinha, apesar da alta taxa de vulnerabiliade à denudação (Crepani et al., 2001), acarreta na formação de um material pedogenético de matriz argilosa que possui menor suscetibilidade à erosão e maior retenção de água criando um substrato favorável à cobertura vegetal e propiciando a formação de uma geofácie de maior umidade no geossistea regional.

\section{Núcleos de terras degradadas: vulnerabilidade do sistema socioeconômico}

Do ponto de vista socioeconômico, a principal atividade antropogênica dos núcleos de terras degradadas é a agropecuária extensiva, de baixíssima inserção tecnológica, praticada principalmente na quadra chuvosa, no caso da agricultura de sequeiro. O manejo da pecuária bovina e caprina, principalmente, além do plantio de milho e feijão é caracterizado por práticas arcaicas de manejo da terra com a "limpeza" total do terreno e elevada densidade animal.

A pecuária extensiva nos NTD’s ocorre, principalmente, nas áreas de litologias das formações Trapiá e Coreaú como arenitos, siltitos e conglomerados, as quais intercalam espacialmente a fácie carbonática da formação Frecheirinha que, por apresentar solos derivados de matriz argilosa dificulta o deslocamento e transporte no período chuvoso em 
função da fina granulometria dos solos que apresentam alto nível de pegajosidade levando ao atolamento de carros e caminhões.

A criação de gado ocupa as áreas mais secas, ou seja, os geótopos áridos do geofácie apropriando-se do conceito de Ab'Saber (1977). A mineração de calcário, por sua vez, ocupa as áreas internas ao campo Aroeiras, onde o sistema solo-planta retém a umidade por mais tempo, compondo uma espécie de geótopo subúmido dada as condições litopedológicas propiciando um ambiente de exceção na paisagem em análise.

A participação da pecuária extensiva na economia regional é evidente, pela alta concentração de rebanho bovino e, culturalmente, pela realização de expressivas vaquejadas nas localidades de Tapadinho e Mosquito (NTD Norte) e cavalgda em São José do Torto (NTD Sul), atraindo vaqueiros de toda a região norte do Estado.

Painel 1- Diferentes diâmetros e espécies vegetais utilizadas na combustão dos fornos em caieiras no município de Coreaú: (A) Localidade de Conceição - NTD Sul; (B) Localidade de Visitação - NTD Norte.
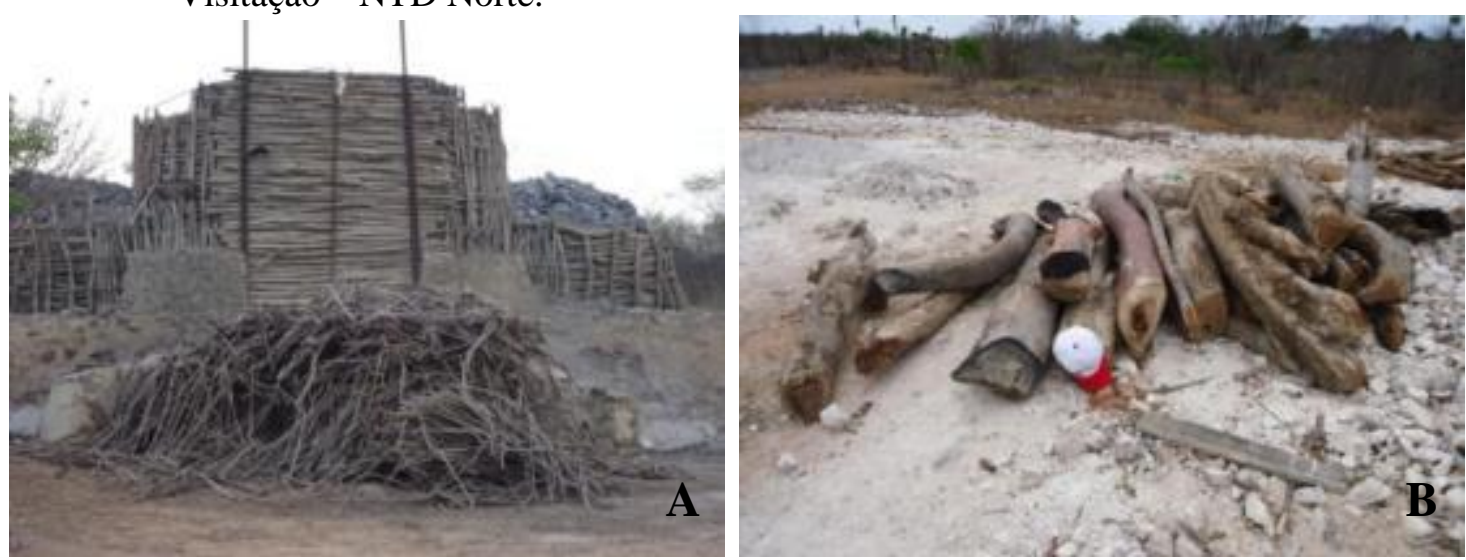

Fonte: Albuquerque (maio, 2014).

A pecuária é um dos principais indicadores da desertificação (MATALLO JÚNIOR, 2001; SÁ et al, 1994) destacando-se negativamente pelo pastoreio e o sobrepastejo de ovinos e caprinos que causam prejuízo a germinação de sementes, à permanência de pequenas mudas e no rebroto da vegetação nativa (SÁ et al., 1994).

O modelo de pecuária extensiva praticado na região consiste na retirada total da cobertura vegetal expondo o solo às precipitações torrenciais típicas de ambientes secos, principalmente, nos primeiros eventos da estação chuvosa que encontram o solo totalmente desprotegido. Após a limpeza total do terreno, a área sofre com excessiva compactação pelo pisoteio dos animais de grande porte (bovinos) e eliminação dos brotos, por parte dos pequenos animais (ovinos e caprinos) (painel 2). 
A pecuária está associada diretamente ao extrativismo vegetal, pois, a retirada de madeira antecede ao uso animal promovendo a limpeza total da área, principalmente, na depressão a qual abastace em grande parte a cadeia produtiva de fabricação da cal (painel 2). Nas áreas mais elevadas e inclinadas dos pequenos maciços é comum constatar a presença de rotas de acesso para retirada de madeira, especialmente o Sabiá (Mimosa caesalpinifolia) para produção de estaca, como relata Costa (2015), na serra da Penanduba, inselberg próximo ao campo calcário homônimo.

Painel 2 - Áreas degradadas com exposição de solo e pavimento pedregoso no município de Coreaú: (A) Localidade de Ubaúna, NTD Sul; (B) Localidade de São Francisco, NTD Norte (set/2013).
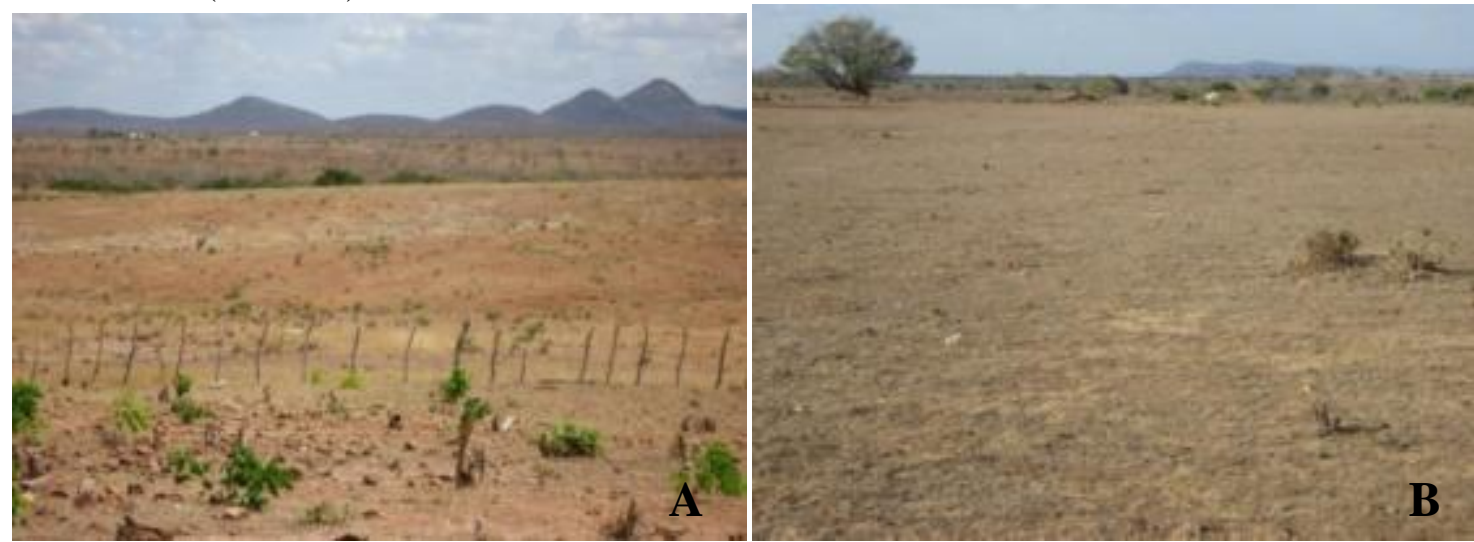

Fonte: Albuquerque (maio, 2014).

As áreas com maiores níveis de degradação localizam-se no NTD Sul, mais exatamente nos arredores do distrito de Ubaúna, localidades de Caia e Conceição. Do ponto de vista dos recursos hídricos, as encostas das áreas de contribuição do açude Trapiá, principal reservatório hídrico do Alto Coreaú (excluindo os açudes Angicos e Boqueirão na sub-bacia do rio Juazeiro) estão entre as áreas mais críticas, principalmente os setores norte e sudeste do açude, bem como o rio Caia, um dos principais afluentes da margem direita do rio Coreaú, este último drenando tambeém parte do NTD Norte (painel 3).

As áreas com maior grau de conservação das terras, por sua vez, estão no interior do campo Aroeiras, formando faixas de transição entre os NTD Norte, Sul e Leste, as quais podem ser identificadas por duas áreas espacialmente representativas: a área de entorno da jazida da fábrica de cimento do grupo Votorantim, no distrito de Aprazível e a área de um plano de manejo florestal entre as localidades de Campo de Dentro e Queimadas (painel 3), respectivamente, nas extremidades leste (município de Sobral) e oeste (município de Coreaú) do campo Aroeiras.

A área da fábrica de cimento constitui-se numa espécie de cinturão verde para amortecimento dos impactos ambientais causados pela mineração, sobretudo, no lado oeste 
da jazida de calcário como o controle da erosão e a retenção do pó calcário, porém, prejudicando a fotossíntese da planta, além de amenizar os impactos da poluição visual.

A outra área é formada por um plano de manejo florestal sustentado da Caatinga na fazenda Campos de Dentro, de propriedade particular, de $6,96 \mathrm{~km}^{2}$, dos quais $4,6 \mathrm{~km}^{2}$ divididos em 15 talhões que são (e serão) explorados diretamente entre os anos de 2011 e 2026, conforme licença da Superintendência Estadual do Meio Ambiente do Estado do Ceará (Semace), tendo como principal produto a lenha e a madeira.

Painel 3. Áreas de maior conservação da Caatinga: (A) explotação de calcário pela fábrica do grupo Votorantim (B) plano de manejo florestal.
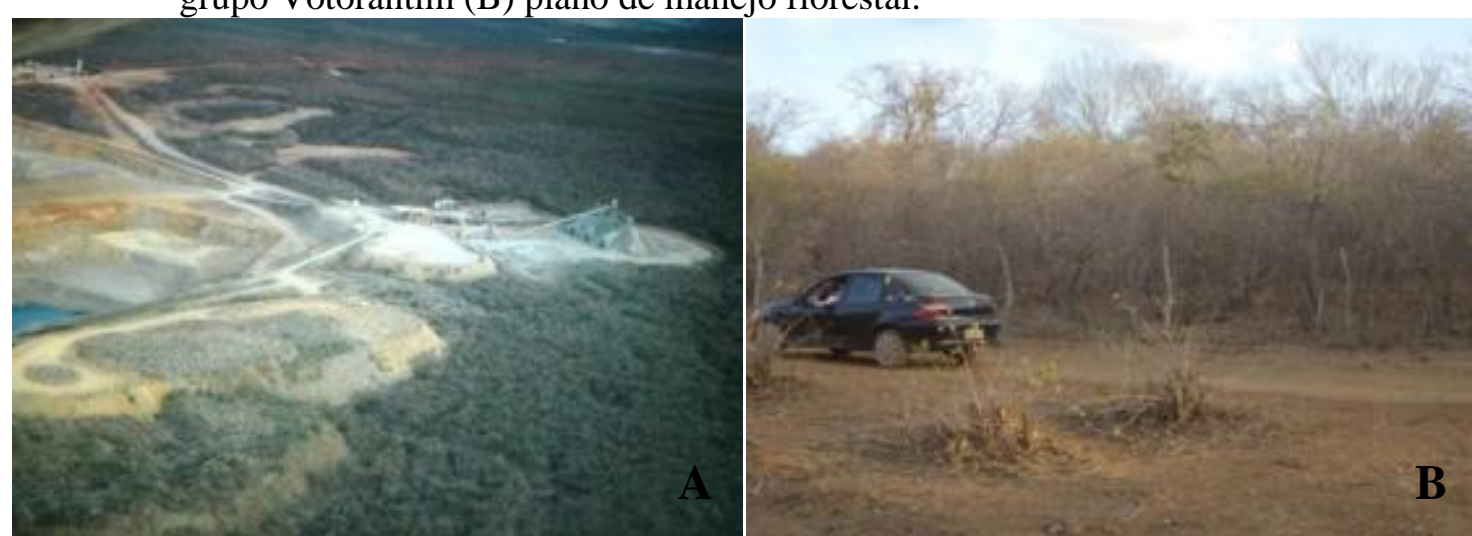

Fonte: Figura A: www.panoramio.com/photo/66334305?source=wapi\&referrer=kh.google.com. Acesso em: 13 maio 2014; Figura B: Autor (2014).

Assim, podemos constatar claramente que as áreas de maior conservação ambiental pertencem a grandes empreendimentos particulares as quais possuem licenciamento ambiental, consequência de elevados investimentos de capital que passa, dentre outras coisas, pela valoração econômica dos recursos naturais, seja, como elemento ou aspecto da paisagem cenário oposto ao da cadeia produtiva da cal na região.

\section{Considerações finais}

A pesquisa permite-nos constatar: a) A baixíssima correlação espacial entre a poligonal do campo calcário Aroeiras e os três núcleos de terras degradadas não ultrapassando 4,5\% de sobreposição; b) O Núcleo de Terra Degradada Sul é o que apresenta as áreas mais degradadas, especialmente, nas localidade de Caia e Conceição, próximo ao distrito de Ubaúna (Coreaú); c) Os núcleos de terras degradadas correspondem litologicamente, quase que de forma exclusiva às formações geológicas Coreaú e Trapiá do grupo Ubajara constituídas por rochas sedimentares depositadas em ambientes fluvial e 
flúvio-marinho; d) Os núcleos de terras degradadas decorrem principalmente dos usos de atividades econômicas como a pecuária bovina e caprino-ovina e do extrativismo vegetal, esta última atendendo a grande demanda de lenha para a combustão dos fornos de cal das dezenas de caieiras espalhadas pela região; e) Os "núcleos" de terras mais conservadas estão associados a um plano de manejo florestal da Caatinga e a área de amortecimento paisagístico e dos impactos ambientais da exploração industrial do calcário para fabricação de cimento revelando, em ambos os casos, a relação direta entre a valoração dos recursos naturais e o estágio de conservação das terras.

No tocante a participação da atividade de mineração, de escala industrial, no processo de desertificação, não é possível nesse nível de escala geográfica e cartográfica fazermos essa constatação, a qual deve-se mostrar mais eficiente na escala dos geótopos, de maior detalhe, pelo que aponta a literatura sobre a temática. Já a mineração de subsistência do calcário realizada de forma artesanal através da exploração de afloramentos rochosos dispersos pelo campo geológico e da lenha como matriz energética, o cenário se apresenta de forma mais preocupante em função do método de extração, localização dispersa e matriz energética utilizadas.

Para finalizar, as áreas fortemente degradadas na bacia hidrográfica do rio Coreaú, especialmente, no alto curso são sempre classificadas pelos estudos de escala estadual como uma extensão do núcleo Irauçuba, mas precisam ser compreendidas como um outro núcleo em função das suas especificidades naturais e socioeconômicas necessitando aprofundamento dos estudos sobre terras degradadas e desertificação em escalas de maior detalhe.

\section{Referências}

AB'SABER, A. N. A problemática da desertificação e da savanização no Brasil. In: Geomorfologia, $n^{\circ}$ 53. São Paulo: USP. 1977. 20 p.

ALBUQUERQUE, F. N. B. Recurso natural, organização espacial e ordenamento territorial: mineração e degradação de terras na Depressão Interplanáltica Semiárida do Alto Coreaú (CE). Rio Claro: IGCE-UNESP. Tese (Doutorado em Geografia). 2015. $223 \mathrm{f}$.

ALBUQUERQUE, F. N. B. Organização espacial das caieiras e fornos de cal no campo calcário Aroeiras, municípios de Coreaú e Sobral (CE): passado e presente. Revista Geociências do Nordeste. vol. 5. No especial. 2019. 
BANCO DO NORDESTE DO BRASIL. A indústria de calcários e dolomitos no Nordeste. Fortaleza: BNB/ETENE. 1987. (Série: Estudos econômicos e sociais, 34). CENTRO DE GESTÃO E ESTUDOS ESTRATEGICOS - CGEE. Desertificação, degradação da terra e secas no Brasil. Brasília: Centro de Gestão e Estudos Estratégicos, 2016.

CHERLET, M. et al. (eds.). World Atlas of Desertification. 3. Ed. Publication Office of the European Union, Luxembourg. 2018.

CORDANI, U. G.; TAIOLI, F. As ciências da Terra: sustentabilidade e desenvolvimento. In Decifrando a Terra. São Paulo: Companhia Editora Nacional. 2009.

COSTA, J. S. Análise geoambiental da Serra da Penanduba (Coreaú/Frecheirinha): bases geográficas voltadas à criação de unidade de conservação. Sobral/CE: UVA. Dissertação (Mestrado em Geografia). 2015. 105 f.

CREPANI, E. et al. Curso de sensoriamento remoto aplicado ao zoneamento ecológicoeconômico. São José dos Campos: INPE, 2001. 25p.

DANTAS, E. W. C. et al. Nordeste brasileiro fragmentado: de uma região com bases naturais a uma fundamentação econômica. In SILVA, J. B. et al. (orgs). Litoral e sertão natureza e sociedade no nordeste brasileiro. Fortaleza: Expressão Gráfica. 2006. p. 23-44. DNPM. Mineração no Semiárido Brasileiro. Brasília. 2009.

FAO. Natural resources and the human environment for good and agriculture.

Environment Paper. no 1 Roma. 1980.

FUNCEME. ICID. Áreas degradadas susceptíveis aos processos de desertificação no

Estado do Ceará. Brasil. Fortaleza: 1992.

GEOPLAN. Relatório de impacto no meio ambiente (RIMA) do projeto de lavra de calcário (DNPM 805.014/75) Coreaú/CE. Grupo Votorantim. vol. II. jan. 1989.

KOPEZINSKI, I. Mineração x meio ambiente: considerações legais, principais impactos ambientais e seus processos modificadores. Porto Alegre: Ed. da UFRGS. 2000.

MATALLO JÚNIOR, H. Indicadores de desertificação: histórico e perspectivas.

Brasília: UNESCO. 2001.

MATALLO JÚNIOR, H. Glossário de termos e conceitos usados no contexto da UNCCD. Brasília: MMA. 2009.

PEREZ-MARIN, A. et al. Núcleos de desertificação no semiárido brasileiro: ocorrência natural ou antrópica? Revista Parcerias Estratégicas. v. 17, n. 34, p. 87-106. Brasília-DF, 2012.

SÁ, I. B. et al. Degradação ambiental e reabilitação natural do trópico semi-árido brasileiro. In: Conferência Nacional e Seminário Latino Americano de Desertificação. Fortaleza, CE. 1994.

SALES, M. C. L. Estudo da degradação ambiental em Gilbués-PI: Reavaliando o “núcleo de desertificação". São Paulo, USP. Dissertação (Mestrado em Geografia). 1997. $181 \mathrm{f}$.

SILVA, I. A. S. Clima e arenização em Gilbués-Piauí: dinâmica das precipitações e a vulnerabilidade da paisagem aos eventos pluviais intensos. Goiânia: IESA-UFG.

Dissertação (Mestrado em Geografia). 2014. 184 f.

UNCCD. United Nations Convention to Combat Desertification in those Countries Experiencing Serious Drought and/or Desertification, particularly in Africa. 1995. WESTING, A. Population, Desertification and Migration. Environmental Conservation, 21 (2), 110-114. 1994. 